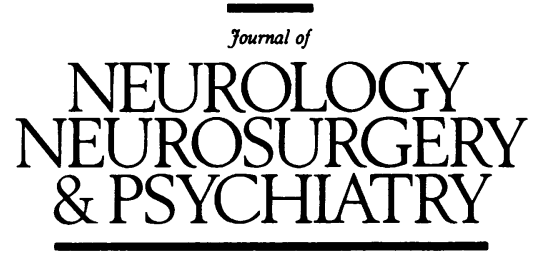

Editorial

\title{
Risk factors for multiple sclerosis: race or place?
}

The contribution made by genetic and environmental factors in determining the distribution of multiple sclerosis has been debated ever since morbidity and mortality statistics were first accurately derived during the 1920 s by Davenport in the United States ${ }^{1}$ and by Allison ${ }^{2}$ in the United Kingdom.

Enthusiasts for the genetic doctrine have included Davenport himself, who suggested that the distribution of multiple sclerosis in North America reflected patterns of immigration from Scandinavia ${ }^{13}$ and Sutherland ${ }^{4}$ who, surveying prevalence rates in Scotland during the 1950s, concluded that Nordic descendants carried a higher risk than Celts. Later, Ebers ${ }^{5}$ re-emphasised the importance of Scandinavian ancestry as a risk factor in North America and provided compelling evidence for the contribution of genetic susceptibility through the assessment of concordance in twins. ${ }^{6}$ Skegg ${ }^{7}$ used the number of Mc/Mac's in the telephone directory to show that multiple sclerosis is common in parts of New Zealand where people of Scottish ancestry are to be found. Swingler, ${ }^{8}$ with others, ${ }^{910}$ correlated the distribution of multiple sclerosis in the United Kingdom with regional variations in the normal frequency of HLA-DR2 and other previously identified markers of genetic susceptibility in northern Europeans.

In concluding that multiple sclerosis is common where there are northern Europeans and drawing on the evidence that by comparison with white populations multiple sclerosis is rare in Oriental, African and Asian populations, and the aboriginal peoples of Australia, New Zealand and the Americas, each of these commentators has argued that genetic factors make a major contribution to the distribution of multiple sclerosis both on a regional and world scale. Furthermore, it is claimed that regional clusters of the disease are found where, for social or historical reasons, genetic isolates exist-both those in which susceptibility genes are by chance over-represented (the Orkney and Shetland Islands) and excluded (the Hutterite communities of north America and Canada) from the population.

Environmentalists have documented the geographical distribution of multiple sclerosis with painstaking care but in contrast to the elaborate interpretations offered by genetic epidemiologists, the facts have often been left to speak for themselves so that the evidence for an environmental agent remains largely circumstantial. The most clearly heard voice has been that of Kurtzke who in repeatedly undertaking the daunting task of collating all publications on the incidence and prevalence of multiple sclerosis, has delineated three zones of risk which, on a world scale, fit a latitudinal gradient $;{ }^{11}$ he has also argued for the existence of point source epidemics notably in the Faroe Islands following World War II, ${ }^{12}$ and others have speculated on the nature of the vectors and agents involved. ${ }^{13}$

The "nurture not nature" lobby has also been much influenced by migration studies showing that the risk of multiple sclerosis in a single ethnic group varies with place of residence perhaps during a critical period in childhood. Depending on the age at emigration, the relocation of Europeans to South Africa reduces,,${ }^{14}$ and the movement of Afro-Asians to Israel increases, ${ }^{15}$ the risk of multiple sclerosis in migrants. The evidence on migration is not entirely straightforward; the increased risk of multiple sclerosis seen in native people moving out of Africa to the United States correlates with the extent to which caucasian genes are introduced into the black community. The genes (one encoded in the class 2 MHC region and the other determining re-arrangements of the $T$ cell receptor) that increase the risk of multiple sclerosis in white populations code for products involved in the immune response against extrinsic antigen ${ }^{16-19}$ so that viral triggers necessarily feature prominently in discussions on the mechanism of genetic susceptibility. Thus the race versus place discussion is to some extent a sterile debate.

This issue of the journal contains three papers that relate more or less directly to this topic. On the question of whether professional contact with patients who have multiple sclerosis increases the risk of developing this disease, the answer is "no" but, for methodological reasons, the study by Dean and colleagues (p899) cannot be regarded as definitive. Developing the theme that $7 / 307$ nurses working in Key West (South Florida) were found to have multiple sclerosis, Dean has compared expected and observed death certifications for multiple sclerosis in medical practitioners and nurses from the United Kingdom using Office of Population Censuses and Surveys statistics and documentary evidence available from the prospective British Doctors' Smoking Study. In neither case does a trend towards increased risk emerge. However, we do not know the degree of contact between patients and these medical staff, and many disorders of proven infective aetiology do not occur more frequently in nurses and doctors; neither is there evidence that more intimate or frequent daily contact with affected individuals increases the risk of multiple sclerosis-conjugal cases are rare.

This study therefore provides no evidence for an increased risk of multiple sclerosis through contact with patients; why seven nurses in Key West should have developed the disease remains unknown but small clusters seemingly linking members of the same school, street, sporting team and other groups are well recognised-the explanation probably lying in statistical chance; these swallows do not make a summer. 
The review paper by Miller et al (p903) ties together the recent authoritative epidemiological study of multiple sclerosis carried out by Simon Hammond in Australia ${ }^{20}$ with contemporary mapping of morbidity and mortality statistics in New Zealand. ${ }^{72}$ The numerators for both areas have been carefully collected and compared with an age adjusted denominator which excludes aboriginal peoplesa potential confounder in northern New Zealand where $16 \%$ of the population are Maori. Since the Mc/Mac differential and normal frequencies of DR2 do not differ between the areas surveyed, Miller concludes that the population at risk is genetically homogeneous and that environmental conditions therefore account for the sevenfold difference in frequency of multiple sclerosis that exists between Queensland and Otago. He might have added that even the highest prevalence rate in these communities largely originating from the United Kingdom is not much more than half the frequency now being observed in most parts of the British Isles, ${ }^{22-24}$ further suggesting that in the context of multiple sclerosis the antipodean environment is protective for northern Europeans.

Sceptics will look more critically at the figures and note that in New Zealand the main step in morbidity occurs across the North Island and that Tasmania has a much higher prevalence than Waikato even though both are of comparable southerly latitude. In fact the whole region falls into two clusters-Hobart (Tasmania), Wellington and Otago (South Island) with rates of $>75 / 10^{5}$ and Queensland, Newcastle (New South Wales) Adelaide (South Australia) Perth (West Australia) and Waikato (North Island of New Zealand) with rates of $<40 / 10^{5}$. Geneticists will argue that the methods used do not exclude significant heterogeneity in the distribution of white populations in Australia or New Zealand, and will question whether the sub tropical climates of Queensland were less acceptable to settlers from the northern parts of Europe and the United Kingdom than the wet foggy highlands of Tasmania and the South Island of New Zealand. The fact that a proportion of the population from Waikato claiming to be white nevertheless has up to $50 \%$ Maori ancestry will also not have escaped the attention of genetic epidemiologists. Sadly, the Mc/Mac index does not differentiate Nordic from Celtic peoples; those in doubt should consult the telephone directories of Glasgow and Belfast.

The paper by Elian, Nightingale and Dean (p906) updating an earlier study ${ }^{25}$ is potentially very important for by claiming that the prevalence of multiple sclerosis in the United Kingdom-born children of West Indian, African and Asian immigrants approximates to that seen in similar age groups among the indigenous people, the authors are providing powerful ammunition for the environmental doctrine. Whether or not readers will be prepared to draw the obvious conclusion that the relative rarity of multiple sclerosis in African and Asian populations in their countries of origin is largely an artefact of environment, will depend on their judgement of three matters: the numerator, the denominator, and whether the observed number of cases deviates from that expected.

The authors have identified several good reasons why the ascertainment of patients prevalent on April 1st 1986, aged over 15 years and born in the United Kingdom of parents who were migrants from the West Indies, Africa or Asia, has been incomplete. Cases will have been missed through relying on the recollections of doctors working in London and the West Midlands and the identification of patients by their surnames. On the other hand, the possibility arises that in accepting the documented diagnosis and not reviewing the evidence, individuals with other diseases will have been included. It is odd that in this cohort both the age of presentation and clinical severity were not typical of multiple sclerosis in white populations; there would be fewer anxieties about the diagnosis if every patient had been tested for HTLV 1 status. The authors have turned some of these criticisms to their advantage by suggesting that only the most severe and early onset cases from among the at-risk cohort have so far been identified, further adding to the claim that the frequency of multiple sclerosis in this group is in reality higher and will rise with time.

Deaths and significant demographic shifts may have occurred in the at-risk immigrant population of London and the West Midlands between the 1971 census and Dr Elian's survey in 1986, making the denominator applied to the index cases inappropriate; the fact that all but one of the 28 West Indian patients were known not to have moved since their parents provided census information in 1971 is only partially reassuring in this respect. In estimating the number of individuals at-risk, it was not possible for $\mathrm{Dr}$ Elian and her colleagues to distinguish individuals of European ancestry returning from Africa in the 1950s or 1960s from black immigrants; census information merely recording that both parents had been domiciled in one of the New Commonwealth countries. Any white individuals developing multiple sclerosis would not have been registered in this study but white repatriates will spuriously have increased the number of children apparently at-risk. The effect of this bias is probably small even though it will have slightly inflated the expected case numbers, but the consequence will once again have been to underestimate the risk of multiple sclerosis in the first generation children of West Indian, African and Asian immigrants.

In calculating the number of children expected to develop multiple sclerosis, Elian and colleagues have used age and sex specific rates available from the 1985 Sutton (Surrey) prevalence study ${ }^{22}$ and assumed an equal risk for immigrants from the new Commonwealth. Much depends on the validity of these expected case numbers; the Sutton study was carried out close to a large urban metropolis where accurate definition of numerator and denominator are more difficult to establish than in population based surveys and non white causes were not excluded. Some readers will also worry about accepting the evidence for an increased risk of multiple sclerosis in the children of immigrants when contemporary figures are not available for the parental generation based on comparable methods of assessment and ascertainment. All the rates cited by Elian necessarily depend on small numbers and are therefore subject to large confidence intervals, a few errors will have made a large impact on the quoted rates and their interpretation. In fact, were it not for a disproportionate number of males aged 20-24, the observed number of cases in West Indian immigrants would have fallen well short of that expected in the population at risk.

The authors make little of the greater risk seen for the children of Asian populations by comparison with black populations, although this difference does reflect racial susceptibility trends, multiple sclerosis having a prevalence of at least $20 / 10^{5}$ in parts of India ${ }^{26}$ but being of legendary rarity in native Africans. Nevertheless, the speed with which the protective effect of being Asian, African or West Indian seems to have been lost upon domicile in the United Kingdom and is such that if these findings are correct, henceforth there will be very little room for population geneticists in discussions on the aetiology of multiple sclerosis. For some this conclusion will add renewed urgency to the need for identifying viral triggers of demyelination; others will wish to be convinced that these preliminary findings in immigrants to the United Kingdom are representative of the disease as a whole.

ALASTAIR COMPSTON

University of Cambridge Clinical School, Addenbrooke's Hospital, Cambridge 

1 Davenport CB. Multiple sclerosis from the standpoint of geographic
distribution and race. Arch Neurol Psychiatry 1922;8:51-8.

2 Allison RT. Disseminated Sclerosis in North Wales. Brain 1931;53: 391-430.

3 Davenport CB. Multiple Sclerosis from the Standpoint of Geographic Distribution and Race. Association for Research in Nervous and Manual Disease 1921;11:8-19.

4 Sutherland JM. Observations on the prevalence of multiple sclerosis in northern Scotland. Brain 1956;79:635-54.

5 Ebers GC, Bulman D. The Geography of MS reflects genetic susceptibility. Neurology 1986;36(suppl 1):108.

6 Ebers GC, Bulman DE, Sadovnick AD, et al. A population based study of multiple sclerosis in twins. New Engl J Med 1986;315:1638-42.

7 Skegg DCG, Corwin PA, Craven RS, et al. Occurrence of multiple sclerosis in the north and south of New Zealand. J Neurol Neurosurg Psychiatry 1987;50:134-9.

8 Swingler RJ, Compston DAS. The distribution of multiple sclerosis in the United Kingdom. J Neurol Neurosurg Psychiatry 1986;49:1115-24.

9 Shepherd DI, Downie AW. Prevalence of Multiple Sclerosis in north east Scotland. Br Med J 1978;2:314-16.

10 Compston DAS. Multiple sclerosis in the Orkney's. Lancet 1981;ii:98.

11 Kurtzke JF. A reassessment of the distribution of Multiple Sclerosis. Parts 1 and 2. Acta Neurol Scand 1975;51:110-57.

12 Kurtzke JF, Hyllested K. Multiple Sclerosis in the Faroe Islands. II. Clinical update, transmission, and the nature of MS. Neurology 1986;36:307-28.

13 Cook SD, MacDonald J, Tapp W, et al. Multiple Sclerosis in the Shetland Islands: an update. Acta Neurol Scand 1988;77:148-51.

14 Dean G. Annual incidence, prevalence and mortality of multiple sclerosis in white South African born and in white immigrants to South Africa. $\mathrm{Br}$ Med $J$ 1976;2:724-30.

15 Leibowitz U, Kahana E, Alter $M$. The changing frequency of multiple sclerosis in Israel. Arch Neurol 1973;29:107-10.
16 Compston DAS. Genetic factors in the aetiology of Multiple Sclerosis. In: McDonald WI, Silberberg DH, eds. Multiple Sclerosis. London: Butterworth, 1986:56-73.

17 Oksenberg JR, Gaiser CN, Cavalli-Svorza LL, Steinman L. Polymorphic markers of human $T$ cell receptor alpha and beta genes. Family studies and comparison of frequencies in healthy individuals and patients with multiple sclerosis and myasthenia gravis. Human Immunology 1988;22:111-21.

18 Oksenberg JR, Stuart S, Begovich AB, et al. Limited heterogeneity of rearranged $\mathrm{T}$ cell receptor $\mathrm{V}$ alpha transcripts in brains of Multiple rclerosis patients. Nature 1990;345:344-6.

erosis patients. Nature 1990;345:344-6.

Seboun E, Robinson MA, Doolitte TH, et al. A susceptibility locus for multiple sclerosis is linked to the T cell receptor beta chain complex. Cell

20 Hammond SR, McLeod JG, Millingen KS, et al. The epidemiology of multiple sclerosis in three Australian cities: Perth, Newcastle and Hobart. Brain 1988;111:1-25.

21 Miller DH, Hornabrook RW, Dagger J, Fong R. Ethnic and HLA patterns related to multiple sclerosis in Wellington, New Zealand. $J$ Neurol Neurosurg Psychiatry 1986;49:43-6.

22 Williams ES, McKeron RO. Prevalence of multiple sclerosis in a south London borough. $\mathrm{Br} \mathrm{Med} J$ 1986;293:237-9.

23 Swingler RJ, Compston DAS. The prevalence of multiple sclerosis in south east Wales. J Neurol Neurosurg Psychiatry 1988;51:1520-4.

24 Roberts M, Martin JP, McLellan DL. Multiple sclerosis in the Southampton district. J Neurol Neurosurg Psychiatry 1990;(in press).

25 Elian M, Dean G. Multiple sclerosis among the United Kingdom born children of immigrants from the West Indies. J Neurol Neurosurg Psychiatry 19899;50:327-32.

26 Bharucha NE, Bharucha EP, Wadia NH, et al. Prevalence of multiple sclerosis in the Parsis of Bombay. Neurology 1988;38:727-9. 